\title{
Local Environmental Predictors of Cholera in Bangladesh and Vietnam
}

\author{
Michael Emch,* Caryl Feldacker, Mohammad Yunus, Peter Kim Streatfield, Vu DinhThiem, Do Gia Canh, and \\ Mohammad Ali \\ Department of Geography, University of North Carolina-Chapel Hill, North Carolina; Carolina Population Center, University of \\ North Carolina -Chapel Hill, North Carolina; Department of Health Behavior and Health Education, University of North \\ Carolina-Chapel Hill, North Carolina; ICDDR,B, Centre for Health and Population Research, Bangladesh; National Institute of \\ Hygiene and Epidemiology, Hanoi, Vietnam; International Vaccine Institute, Seoul, Korea
}

\begin{abstract}
Environmental factors have been shown to be related to cholera and thus might prove useful for prediction. In Bangladesh and Vietnam, temporal cholera distributions are related to satellite-derived and in-situ environmental time series data in order to examine the relationships between cholera and the local environment. Ordered probit models examine associations in Bangladesh; probit models examine associations at 2 sites in Vietnam. Increases in ocean chlorophyll concentration are related to an increased magnitude of cholera in Bangladesh. Increases in sea surface temperature are most influential in Hue, Vietnam, whereas increases in river height have a significant role in Nha Trang, Vietnam. Cholera appearance and epidemic magnitude are related to the local environment. Local environmental parameters have consistent effects when cholera is regular and more prevalent in endemic settings, but in situations where cholera epidemics are rare there are differential environmental effects.
\end{abstract}

\section{INTRODUCTION}

Although our understanding of cholera significantly increased during the past 20 years, cholera prevalence remains high in many areas of the world. Currently, no predictive model exists to help health departments prepare for or prevent outbreaks. This paper investigates whether local environmental information can be used to predict cholera outbreaks. The specific aims are to 1) describe the temporal fluctuations of cholera during the past 20 years in three study areas; 2) examine the role of local environmental drivers of cholera including sea surface temperature, sea surface height, ocean chlorophyll concentration, rainfall, ambient temperature, and river height/discharge; and 3) compare associations between the local environment and cholera across 3 study sites in Bangladesh and Vietnam. This study measures the spatiotemporal associations between cholera incidence and environmental variables derived from satellite imagery (i.e., ocean chlorophyll concentration, sea surface temperature, sea surface height) and in-situ data (i.e., rainfall, temperature, river discharge/height).

Previous studies do not test the associations between environmental variables and cholera outbreaks over such a long time period nor do they examine satellite-derived and in-situ environmental data simultaneously. ${ }^{1}$ Current predictive and preventive efforts for cholera are limited, and the response is usually reactive. ${ }^{2}$ Additionally, the efficacy of cholera vaccines is limited and wanes after short periods of time, especially in children. ${ }^{3}$ Although responding to cholera after an outbreak is effective in preventing deaths and slowing the spread of infection, an early warning system with at least 2-months' lead time could cue the vaccination of high-risk groups, increasing the immunity of communities and reducing overall morbidity and mortality. ${ }^{3,4}$ The World Health Organization (WHO) recognizes these potential linkages and notes that cholera is an epidemic infectious disease with good potential for developing early warning systems based on climate/environmental drivers. ${ }^{2}$ Therefore, this paper develops

* Address correspondence to Michael Emch, Department of Geography, 205 Saunders Hall, CB 3220, University of North CarolinaChapel Hill, Chapel Hill, NC 27599. E-mail: emch@unc.edu and tests probability models for cholera magnitude and outbreaks based on hypothesized linkages between environmental factors and cholera outbreaks.

\section{BACKGROUND}

In some endemic areas of the world, cholera outbreaks have predictable seasonal patterns. In Bangladesh, epidemics occur twice a year in the spring and fall, before and after the monsoons. ${ }^{5-8}$ The bacteria that cause cholera, Vibrio cholerae, can be isolated from patients as well as from the aquatic environment. ${ }^{6-13}$ Until recently, the reservoirs or sites of survival and multiplication of $V$. cholerae during interepidemic periods were unknown. Recent studies provide more satisfactory explanations of how seasonality and endemicity of cholera are maintained, providing clues about interannual variability as well. ${ }^{14}$

Aquatic flora, including algae and phytoplankton, are hypothesized to serve as reservoirs of $V$. cholerae. $^{6,11,15}$ Other literature suggests that aquatic fauna, such as zooplankton and copepods, also play an important role as an environmental reservoir for cholera. ${ }^{16,17}$ Lobitz and others hypothesized that the warming of the local sea surface temperature influences the growth of phytoplankton concentrations and that sea surface height increases human-vibrio contact by transporting the bacteria into inland waters through the tidal intrusion of plankton. ${ }^{1}$ The hypothesized associations and patterns between local- or regional-level climate and cholera can be indirectly measured using satellite imagery. Using satellite sensors, Lobitz and others found that both sea surface temperature and sea surface height in the Bay of Bengal are correlated with temporal fluctuations of cholera in Dhaka, Bangladesh, from 1992 to $1995 .{ }^{1}$ Other research echoes these findings, concurring that increases in sea surface temperature facilitate phytoplankton growth, which in turn encourages the subsequent multiplication of commensal copepods. ${ }^{18,19}$

Temporal fluctuations in cholera are likely related to variations in physical and nutritional aquatic parameters, ${ }^{20}$ including conditions in both ocean reservoirs and the brackish ponds and canals of rural Bangladesh. ${ }^{21,22} \mathrm{~V}$. cholerae survival appears to be dependent on abiotic characteristics including alkalinity, salinity, and iron concentration ${ }^{23,24}$ that 
influence the expression of virulence genes such as those that regulate the cholera toxin, the toxin responsible for watery diarrhea. ${ }^{25,26}$ Salinity may also partially explain the seasonal variation of cholera. ${ }^{24} \mathrm{~V}$. cholerae may be unable to persist in winter with colder water temperatures; however, aquatic reservoirs with salinities of $0.5-3.0 \%$ and temperatures consistently above $25^{\circ} \mathrm{C}$ may maintain cholera in endemic areas. ${ }^{27}$

Based on the disease ecology literature described above, it is hypothesized that increases in ocean chlorophyll concentration, sea surface temperature, and sea surface height will be positively associated with cholera magnitude and/or the appearance of outbreaks. It is also expected that increases in river height and river discharge will be negatively associated with cholera because of a dilution effect, a possible effect caused by the lower bacterial concentration due to more fresh water coming into the aquatic environment. ${ }^{28}$

\section{MATERIALS}

Study areas. Cholera incidence time series and contemporaneous environmental variables are compiled for Matlab, Bangladesh (Figure 1) from 1983 to 2003. These same variables are compiled from Hue and Nha Trang, Vietnam (Figure 2), from 1985 to 2003. Matlab is the field area for the International Center for Diarrheal Disease Research, Bangladesh (ICDDR,B), a research institute that implements a health and demographic surveillance system. Matlab is in south-central Bangladesh, a region of endemic cholera approximately 50 kilometers southeast of Dhaka, adjacent to the confluence of the Ganges and Meghna rivers. Stool samples are taken from all patients who are admitted to the Matlab hospital, and the laboratory routinely tests for cholera. In Vietnam, cholera data are collected through a surveillance program implemented by the National Institute of Hygiene and Epidemiology (NIHE). NIHE conducts cholera

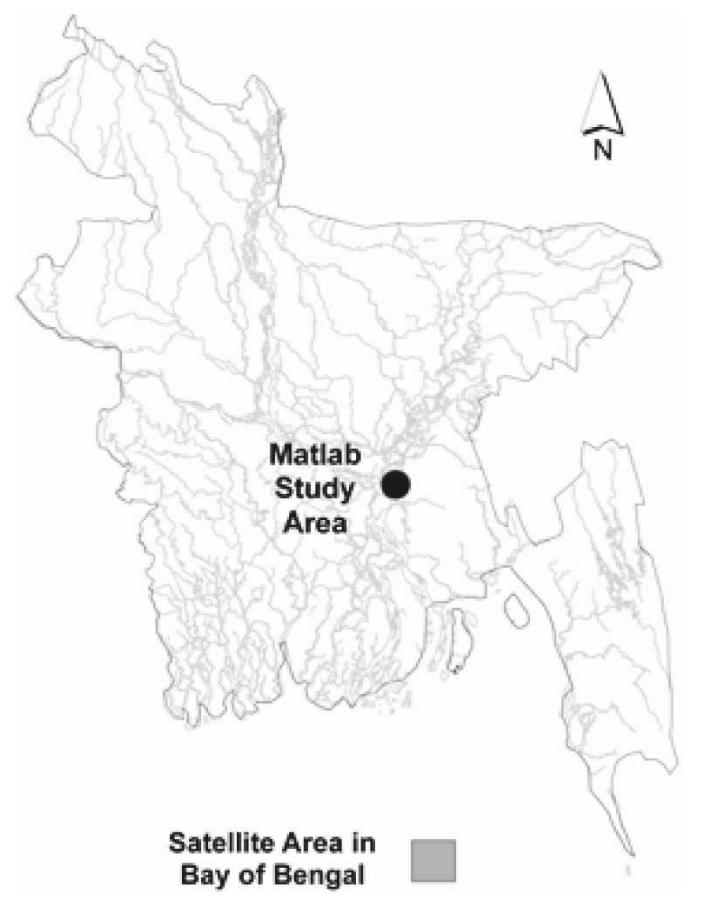

Figure 1. Bangladesh study area.

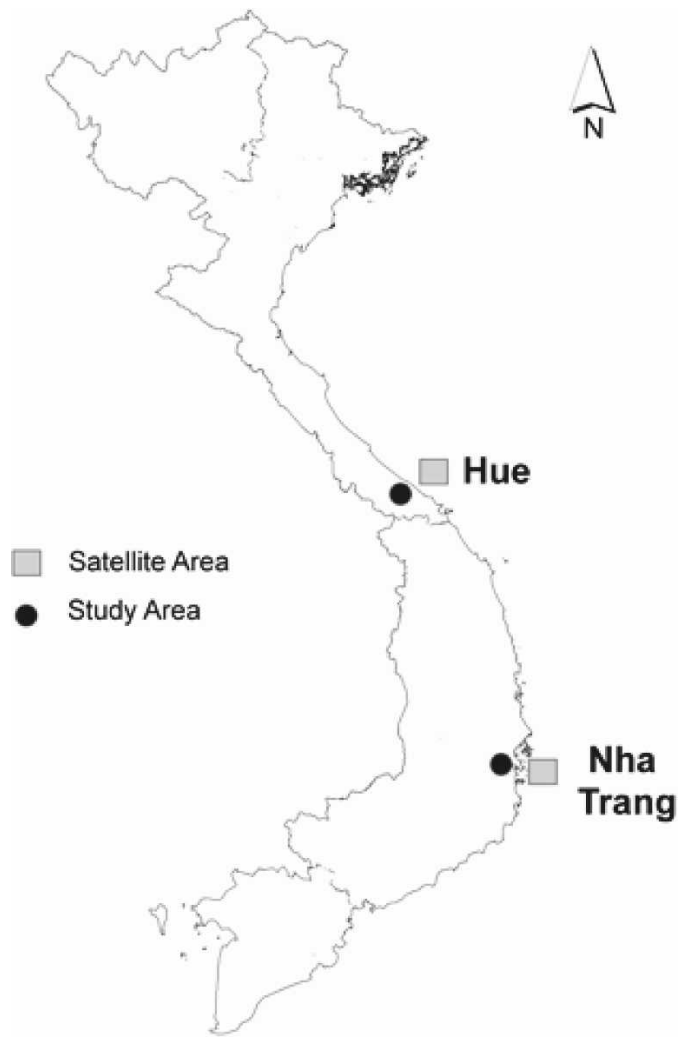

Figure 2. Vietnam study areas.

surveillance through its provincial Centers of Preventive Medicine, including sites in both Vietnam study areas. In both Vietnam sites, cholera cases are reported based on patient symptoms. Laboratory confirmation of cholera is conducted on a sample of cases for verification. Hue and Nha Trang are both in coastal regions of Vietnam. Hue is separated from the ocean by several kilometers of estuary; Nha Trang is adjacent to the ocean.

Environmental data. Table 1 summarizes source information for the environmental variables. Summary statistics for each study site are displayed in Tables 2-4. For all 3 sites, mean monthly sea surface temperature, sea surface height, and ocean chlorophyll concentration are derived from satellites. The satellite data for the sea surface temperature variables are available beginning in January 1985 and are distributed by NASA's Jet Propulsion Laboratory. The AVHRR sensor collects data for 4-km areas. This analysis is based on $8 \times 8$ pixel areas; each record represents an average value for a $32 \mathrm{~km} \times 32 \mathrm{~km}\left(1024 \mathrm{~km}^{2}\right)$ area. Sea surface height, which is a measure of sea-level anomalies, is derived through satellite altimetry and is available from 1992 from the TOPEX/ Poseidon sensor and also from the Jason-1 sensor from 2002. Starting in 1997, ocean chlorophyll concentration data are available from SeaWiFS, a sensor that remotely measures chlorophyll concentration at a spatial resolution of $9 \mathrm{~km}$. Approximately the same area is used to compile these satellitederived, monthly environmental variables for all 3 sensors (Figures 1 and 2).

Environmental variables from in-situ sources include monthly ambient temperature, rainfall, and river discharge/ height (Tables 2-4). The source for the Bangladesh in-situ 
TABLE 1

Environmental variables and data sources for Bangladesh and Vietnam sites

\begin{tabular}{ll}
\hline \multicolumn{1}{c}{ Variable } & Data source and availability \\
\hline $\begin{array}{l}\text { Satellite-derived environmental } \\
\text { variables }\end{array}$ & \\
$\begin{array}{c}\text { Ocean chlorophyll } \\
\text { concentration }\end{array}$ & SeaWiFS (1997-2003) \\
Source: http:// & oceancolor.gsfc.nasa.gov/ \\
Sea surface temperature & AVHRR (1985-2003) \\
& Source: http:// \\
poet.jpl.nasa.gov/ \\
Sea surface height & TOPEX/Poseidon (1992- \\
& 2003), Jason-1 (2002- \\
& 2003) \\
& Source: http:// \\
www.aviso.oceanobs.com/ \\
In-situ environmental variables & Weather stations in \\
Rainfall & Chandpur, \\
& Bangladesh (1983-2003); \\
& Hue and Nha Trang, \\
& Vietnam (1985-2003) \\
& Weather stations in \\
Chandpur, \\
Bangladesh (1983-2003); \\
Hue and Nha Trang, \\
Vietnam (1985-2003) \\
Gauges in Demra, \\
Bangladesh (1983-1993) \\
and Bhairab, \\
Bangladesh (1983-1988); \\
gauges in Hue and Nha \\
Trang, Vietnam (1985- \\
2003) \\
\hline
\end{tabular}

data is the Water Resources Planning Organisation, which monitors water resources using a network of observation stations throughout the country. The closest 2 river discharge stations to the Matlab study area, Demra and Bhairab, are included in the analysis. Discharge at Demra was recorded from June to October from 1983 to 1993 and at Bhairab from 1983 to 1988. Ambient temperature and rainfall are available from 1983 to 2003 in Chandpur, which is just outside the study area. In Vietnam, the environmental data are collected by the Hydro-Meteorological Service of Vietnam, a government agency that maintains a national network of meteorological and hydrological stations. In both Hue and Nha Trang, Vietnam, ambient temperature, rainfall, and river height/ discharge data are available from late 1985 to 2003. River height is available on the river flowing into Hue, the Perfume River, and on 2 rivers flowing into the Nha Trang study area (the Cai and Dinh rivers). River discharge is also available for the Cai River.
Cholera data: Bangladesh. The monthly cholera cases for the Matlab, Bangladesh, research site were collected through the ICDDR,B surveillance system from 1983 to 2003. Figure 3 shows monthly cholera incidence fluctuation in Bangladesh over the entire study period. In Bangladesh, there are always cholera cases, and seasonal fluctuations are expected. Therefore, in Bangladesh we examine the factors that make a month's cholera outbreaks extraordinarily higher than the same month in other years. The first outcome looks at factors that predict a high monthly outbreak. A "high" outbreak is defined as a monthly outbreak that has more cholera cases than $70 \%$ of outbreaks during the same calendar month of other years. The second outcome looks at factors that predict an extreme magnitude cholera month. An "extreme" outbreak is defined as a monthly outbreak that has a larger number of cholera cases than $85 \%$ of outbreaks during the same calendar month of other years.

Two separate, ordinal outcome variables of cholera magnitude, "high" and "extreme," are created by categorizing the average monthly cholera cases. To create these variables, first, all 21 years of data are sorted by month. For each month-only grouping, the data are ordered based on the number of cholera cases. For high cholera, the ranking system assigns the value " 1 " to the months with the fewest $30 \%$ of cholera cases (low), the value " 2 " for the months within the middle $40 \%$ of cholera cases (medium), and the value " 3 " for the months with the highest $30 \%$ of all cholera cases (high). For example, all 21 years of February observations are grouped and ordered based on cholera cases. The years with the lowest $30 \%$ of February cholera cases receive the ranking of 1 (low); the years with the middle $40 \%$ of February cholera cases receive the ranking of 2 (medium); and the years with the highest $30 \%$ of all February cholera cases receive the ranking of 3 (high). After assigning the relative, within-month rank, the data are resorted by month and year, treating each month as an observation with a ranking coded 1,2 , or 3 . The same procedures are followed to create the outcome variable of extreme cholera, coding " 1 " for the lowest $15 \%$ of months (low), " 2 " for the middle $70 \%$ (medium), and " 3 " for the highest $15 \%$ (extreme). The high and extreme categories are most important for this analysis as prediction of, and preparation for, months with higher than expected cholera would bring the highest potential benefits to the community.

Cholera data: Vietnam. Data on monthly cholera cases are available in Hue from 1985 to 2003 and in Nha Trang from 1985 to 1995 . Figures 4 and 5 illustrate the sporadic cholera epidemics in the 2 Vietnam study areas. There are no reported cholera cases in Nha Trang after 1995; the reason for the disappearance is unknown. Because cholera epidemics

TABLE 2

Monthly average of cholera and environment variables in Matlab, 1983-2003

\begin{tabular}{|c|c|c|c|c|c|}
\hline Variable & $N$ months & Mean & SD & Min. & Max. \\
\hline No. of cholera cases & 252 & 34.69 & 44.58 & 1 & 327 \\
\hline Ocean chlorophyll concentration $\left(\mathrm{mg} / \mathrm{m}^{3}\right)$ & 75 & 0.42 & 0.41 & 0.18 & 2.49 \\
\hline Sea surface temperature $\left({ }^{\circ} \mathrm{C}\right)$ & 228 & 25.66 & 5.33 & 0.06 & 31.37 \\
\hline Sea surface height $(\mathrm{cm})$ & 135 & 0.75 & 8.95 & -20.81 & 18.21 \\
\hline Ambient temperature $\left({ }^{\circ} \mathrm{C}\right)$ & 228 & 30.61 & 2.68 & 22.42 & 35.13 \\
\hline Rainfall (mm) & 243 & 5.82 & 5.65 & 0.00 & 29.98 \\
\hline River discharge at Bhairab $\left(\mathrm{m}^{3} / \mathrm{s}\right)$ & 104 & 7114.89 & 4869.89 & 75.29 & 17245.16 \\
\hline \multicolumn{6}{|l|}{ River discharge at } \\
\hline $\operatorname{Demra}\left(\mathrm{m}^{3} / \mathrm{s}\right)$ & 61 & 1307.15 & 360.63 & 244.39 & 2257.00 \\
\hline
\end{tabular}


TABLE 3

Monthly average of cholera and environment variables in Hue, 1985-2003

\begin{tabular}{|c|c|c|c|c|c|}
\hline Variable & $N$ months & Mean & SD & Min. & Max. \\
\hline Cholera incidence $/ 1,000,000$ & 253 & 34.08 & 242.23 & 0 & 2707 \\
\hline \multicolumn{6}{|l|}{ Ocean chlorophyll } \\
\hline concentration $\left(\mathrm{mg} / \mathrm{m}^{3}\right)$ & 100 & 0.544 & 0.342 & 0.149 & 2.37 \\
\hline Sea surface temperature $\left({ }^{\circ} \mathrm{C}\right)$ & 228 & 26.50 & 3.57 & 8.12 & 31.29 \\
\hline Sea surface height $(\mathrm{cm})$ & 148 & 2.31 & 13.76 & -24.12 & 34.51 \\
\hline Ambient temperature $\left({ }^{\circ} \mathrm{C}\right)$ & 228 & 25.1 & 3.40 & 17.9 & 30.2 \\
\hline Rainfall (mm) & 228 & 254.33 & 330.30 & 3.00 & 2451.70 \\
\hline Perfume River height (cm) & 240 & 12.60 & 31.11 & -26.53 & 122.00 \\
\hline
\end{tabular}

are infrequent and there are no cholera cases between outbreaks, the dependent variable for cholera in both Hue and Nha Trang is created by dichotomizing the monthly cholera cases. Months with 1 or more cholera cases are coded " 1 "; months with no recorded cholera cases are coded " 0. "

\section{METHODS}

To investigate the relationships between cholera and the environment, an exploration of patterns over time is necessary. In Bangladesh, higher cholera incidence is expected just before and after the monsoon, but some seasonal epidemics are worse than others. Because there is always cholera in Bangladesh, it is important to understand why some months have extraordinarily higher levels than the same month in other years. Therefore, in Bangladesh, we examine the environmental factors that predict when an outbreak might have higher incidence rates than expected. In Vietnam, seasonal patterns are apparent, but outbreaks do not occur every year. Therefore, examination of the environmental factors that predict when an outbreak might occur is necessary. In all 3 study sites, there are anomalies in both environmental factors and cholera cases. It is hypothesized that these extraordinary seasonal and monthly effects are the key to understanding the relationships between the environment and cholera.

It is also possible that environmental factors have a delayed effect on cholera outbreaks; therefore, 2-month lag effects of each independent variable are created. Because the ultimate goal of this project is to determine whether and how environmental variables can be used in an early warning system, it makes sense to examine the relationships before cholera epidemics occur. A correlation matrix between variables and their individual lag effects reveal low correlations; therefore, variables and their lag effects are tested simultaneously.

Bivariate and multivariate statistical models are built and tested using STATA 9.0. For Bangladesh, an ordered probit model is built to analyze 2 separate, ordinal outcomes: "high" cholera and "extreme" cholera. For Vietnam, probit models are built for the dichotomous outcome. All models use robust standard errors. To test for significance in bivariate models, Wald $\chi^{2}$ and $z$ statistics are calculated with significance reported at the $P<0.05, P<0.01$, and $P<0.001$ levels. In multivariate models, $z$ statistics are used to assess significance of individual variables. Wald $\chi^{2}$ and log-likelihoods assess significance of the overall model. High correlations between significant variables limit multivariate model development.

\section{RESULTS}

Table 5 shows the results of the ordered probit models that estimate when monthly outbreaks in Bangladesh are high or extreme in comparison to the same month in other years. Ocean chlorophyll concentration is found to be positively and significantly associated with both high and extreme cholera outbreaks, and the 2-month lag effects are also significant and positively associated with increasing cholera magnitude. River discharge at Bhairab is significant and negatively associated with the probability of both high and extreme cholera at the 0.05 level. Lastly, river discharge at Demra is negatively associated with the probability of increasing cholera magnitude; it is only significant in the extreme cholera model at the 0.05 level. Sea surface temperature, rainfall, sea surface height, and temperature are not significantly associated with cholera magnitude.

The effects of increases in environmental factors on the relative magnitude of monthly cholera outbreaks are calculated using marginal effects statistics. ${ }^{29}$ The resulting probabilities predict the average impact of an increase in one standard deviation in significant variables on the probability of an outbreak that is high ( $>70$ th percentile) or extreme $(>85$ th percentile) in comparison to the same month in other years. The results are presented in Figure 6. The results for the

TABLE 4

Monthly average of cholera and environment variables in Nha Trang, 1985-1995

\begin{tabular}{|c|c|c|c|c|c|}
\hline Variable & $N$ months & Mean & SD & Min. & Max. \\
\hline Cholera incidence $/ 1,000,000$ & 131 & 26.26 & 121.59 & 0 & 1302 \\
\hline Ocean chlorophyll concentration $\left(\mathrm{mg} / \mathrm{m}^{3}\right)$ & 101 & 0.42 & 0.30 & 0.09 & 2.06 \\
\hline Sea surface temperature $\left({ }^{\circ} \mathrm{C}\right)$ & 228 & 27.00 & 2.73 & 10.02 & 30.52 \\
\hline Sea surface height $(\mathrm{cm})$ & 148 & 0.70 & 7.81 & -23.37 & 16.43 \\
\hline Ambient temperature $\left({ }^{\circ} \mathrm{C}\right)$ & 131 & 26.59 & 1.76 & 22.90 & 29.60 \\
\hline Rainfall (mm) & 131 & 96.74 & 121.58 & 0.10 & 549.20 \\
\hline Dinh River height $(\mathrm{cm})$ & 215 & 272.95 & 39.16 & 110.26 & 386.53 \\
\hline Cai River height $(\mathrm{cm})$ & 228 & 462.42 & 61.06 & 381.45 & 717.45 \\
\hline Cai River discharge $\left(\mathrm{m}^{3} / \mathrm{s}\right)$ & 228 & 73.33 & 85.24 & 9.08 & 520.16 \\
\hline
\end{tabular}




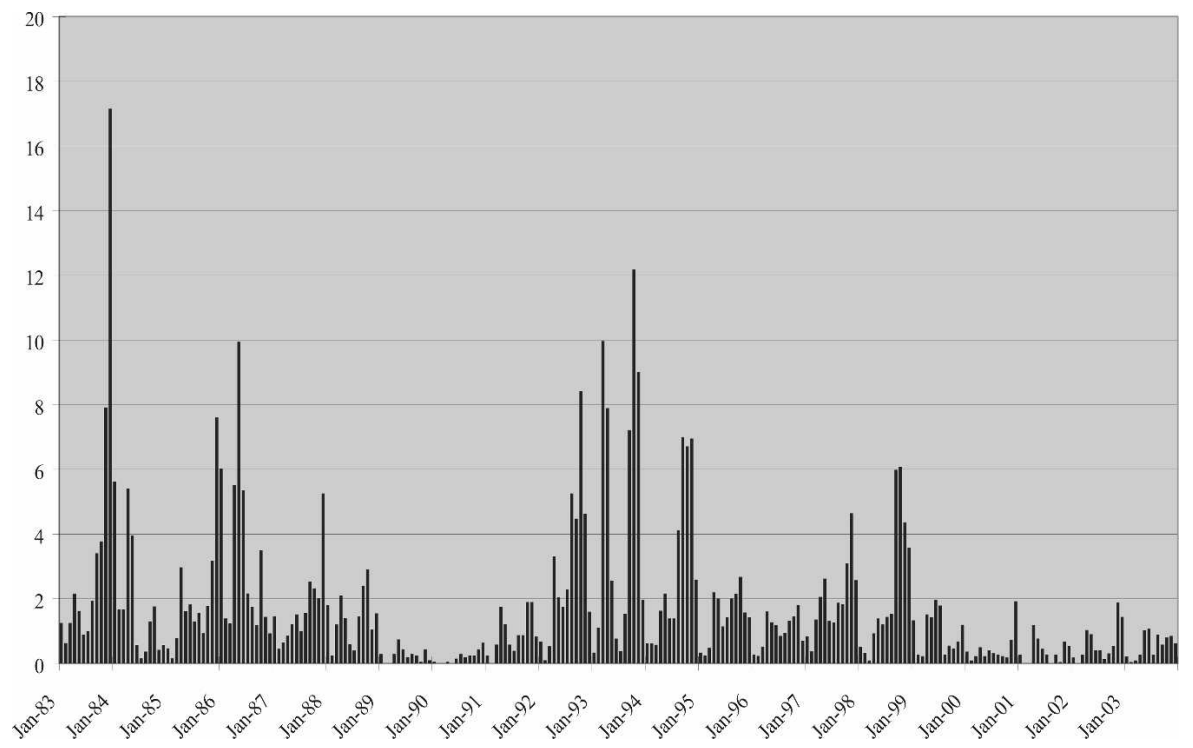

FIGURE 3. Cholera cases per 10,000 in Matlab, Bangladesh, by month: 1983-2003.

high-magnitude category indicate that for every $0.41 \mathrm{mg} / \mathrm{m}^{3}$ increase in ocean chlorophyll concentration, the probability of a having a high monthly outbreak increases by $13.2 \%$. The 2-month lag effects are also strong raising the probability of a high monthly outbreak by $24.5 \%$. In contrast, an increase in $4870 \mathrm{~m}^{3} / \mathrm{s}$ of river discharge at Bhairab decreases the likelihood of a high outbreak by $9.3 \%$. The effects of an increase at Demra are similar to those at Bhairab; an increase of 360 $\mathrm{m}^{3} / \mathrm{s}$ discharge decreases the likelihood of a high month by $7.6 \%$. The results for the extreme magnitude category $(>85$ th percentile) are also calculated. The effects of an increase in ocean chlorophyll concentration and its 2-month lag are posi- tive, but smaller. An increase in $0.41 \mathrm{mg} / \mathrm{m}^{3}$ of ocean chlorophyll concentration raises the probability of an outbreak that is extreme by $3.6 \%$. A similar rise in its 2-month lag increases the likelihood by $2.6 \%$. In Bhairab, an increase of $4870 \mathrm{~m}^{3} / \mathrm{s}$ of river discharge decreases the likelihood of an extreme outbreak by $5.5 \%$. Lastly, in Demra, an increase in $360 \mathrm{~m}^{3} / \mathrm{s}$ decreases the probability of an extreme outbreak by $5.9 \%$.

Table 6 shows the probit model results estimating the probability of cholera outbreaks in Hue. River height, sea surface height, sea surface height 2-month lag, and rainfall 2-month lag have negative and significant associations with cholera outbreaks in the bivariate analysis. Sea surface temperature

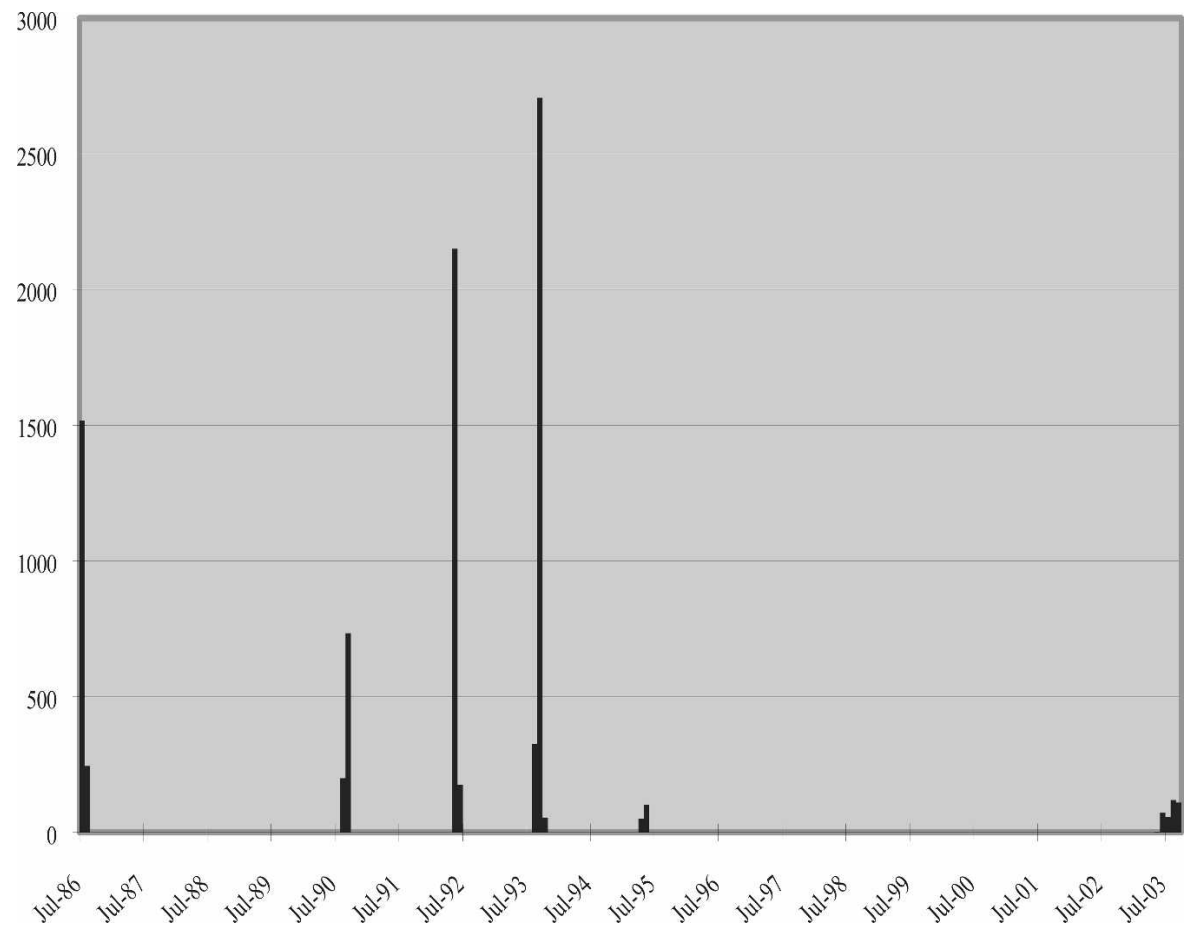

FIGURE 4. Cholera cases per million in Hue, Vietnam: 1986-2003. 


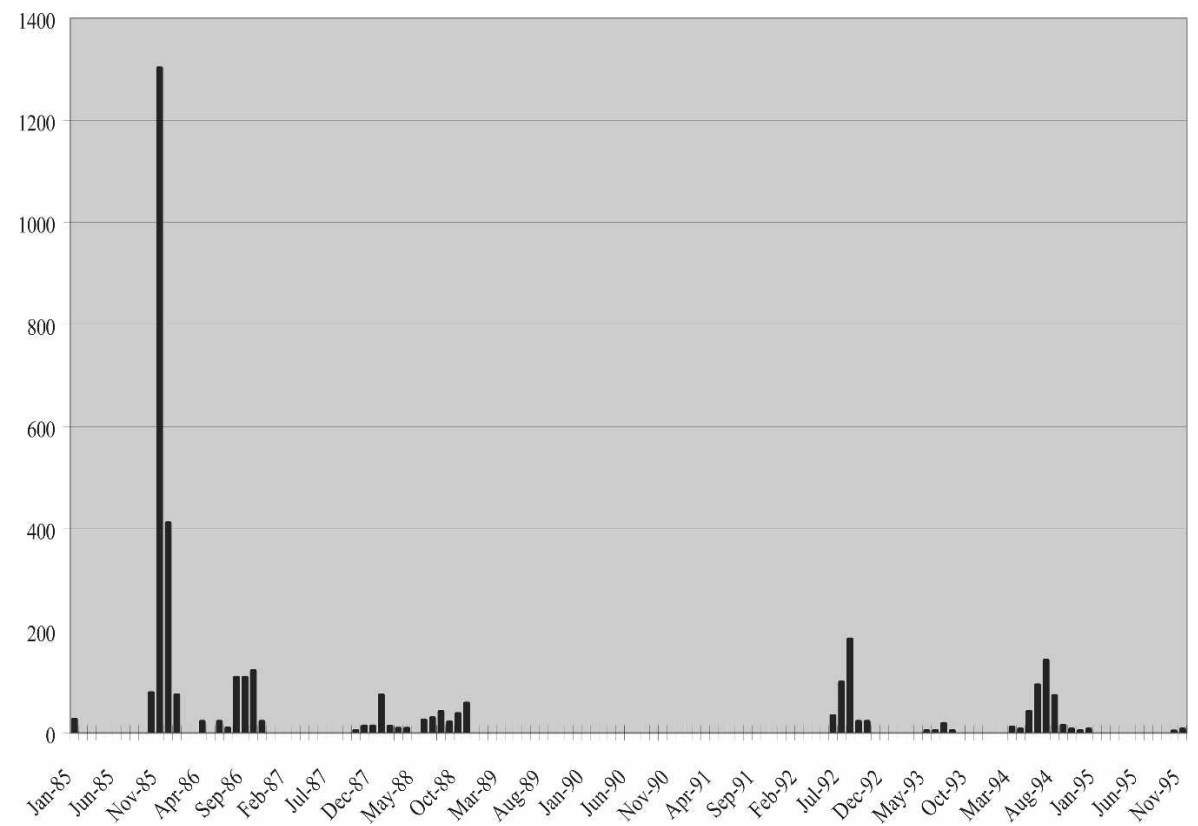

FIgURE 5. Cholera cases per million in Nha Trang, Vietnam: 1985-1995.

has a positive and significant effect on the probability of cholera outbreak. Ocean chlorophyll concentration and temperature are not significantly associated with the probability of cholera outbreak. In multivariate analysis, the effect of sea surface temperature has a significant, positive effect on the probability of cholera outbreak when controlling for sea surface height.

The predicted effects of an increase in one standard deviation in significant environmental variables on the probability of a cholera outbreak in Hue are calculated (Figure 7). For every $31-\mathrm{cm}$ increase in river height, the probability of cholera decreases by $2.9 \%$; the same increase in its 2 -month lag effect decreases the probability of outbreak by $6.3 \%$. Most striking, for every $3.6^{\circ} \mathrm{C}$ increase in sea surface temperature, the probability of cholera increases by $15 \%$. In the multivariate model, for every $3.6^{\circ} \mathrm{C}$ increase in sea surface temperature, the probability of cholera increases by $12.2 \%$, controlling for the effects of sea surface height.

Table 7 shows the results of the probit models to estimate the probability of cholera outbreaks in Nha Trang. Monthly rainfall, Cai River height, Dinh River height, Dinh River height 2-month lag, and Cai River discharge have positive and significant effects on the probability of cholera outbreaks. Sea surface temperature, sea surface height, and ambient tem- perature are not significantly associated with the probability of cholera outbreaks. In multivariate analysis, the effect of Dinh River height has a significant, positive effect on the probability of cholera outbreak while controlling for the height of the Cai River.

The predicted effects of an increase in one standard deviation in significant environmental variables on the probability of cholera outbreaks in Nha Trang are calculated (Figure 8). For every 121-mm increase in rainfall, the probability of cholera increases by $9.8 \%$, and for every $61-\mathrm{cm}$ increase in Cai River height, the probability of cholera increases by $8.8 \%$. Moreover, an increase in $39 \mathrm{~cm}$ in the Dinh River increases the probability of cholera by $14 \%$ while the same increase in its 2-month lag increases the probability of cholera by $10 \%$. Lastly, an increase of $85 \mathrm{~m}^{3} / \mathrm{s}$ in Cai River discharge increases the probability of cholera by $11.6 \%$. In the multivariate model, for every 39-cm increase in Dinh River height, the probability of cholera increases by $14.3 \%$, controlling for Cai River height.

\section{DISCUSSION}

In Bangladesh, increases in ocean chlorophyll concentration are associated with increasing cholera, and this effect is

TABLE 5

Relationship between cholera magnitude and the environment in Matlab, Bangladesh

\begin{tabular}{lccr}
\hline \multicolumn{1}{c}{ Variable } & $N$ & High $(>70$ th percentile $)$ & Extreme $(>85$ th percentile) \\
\hline Ocean chlorophyll concentration & 75 & $1.47 * * *(0.443)$ & $0.955^{* *}(0.367)$ \\
Ocean chlorophyll concentration 2-month lag & 75 & $2.75 * * *(0.695)$ & $0.654^{*}(0.275)$ \\
River discharge at Bhairab & 104 & $-0.0000546 *(0.0000217)$ & $-0.0000473 *(0.0000213)$ \\
River discharge at Demra & 61 & $-0.000677(0.000379)$ & $-0.000905 *(0.000390)$ \\
Sea surface temperature & 228 & $0.0138(0.014)$ & $-0.004(0.012)$ \\
Rainfall & 243 & $-0.003(0.012)$ & $0.002(0.013)$ \\
Sea surface height & 135 & $-0.005(0.0105)$ & $-0.011(0.013)$ \\
Temperature & 228 & $0.011(0.026)$ & $0.003(0.027)$ \\
\hline
\end{tabular}

Results of Wald $\chi^{2}$ from ordered probit model, bivariate analysis: $* P<0.05, * * P<0.01,{ }^{*} * * P 0.001$. Robust standard errors in parentheses. 


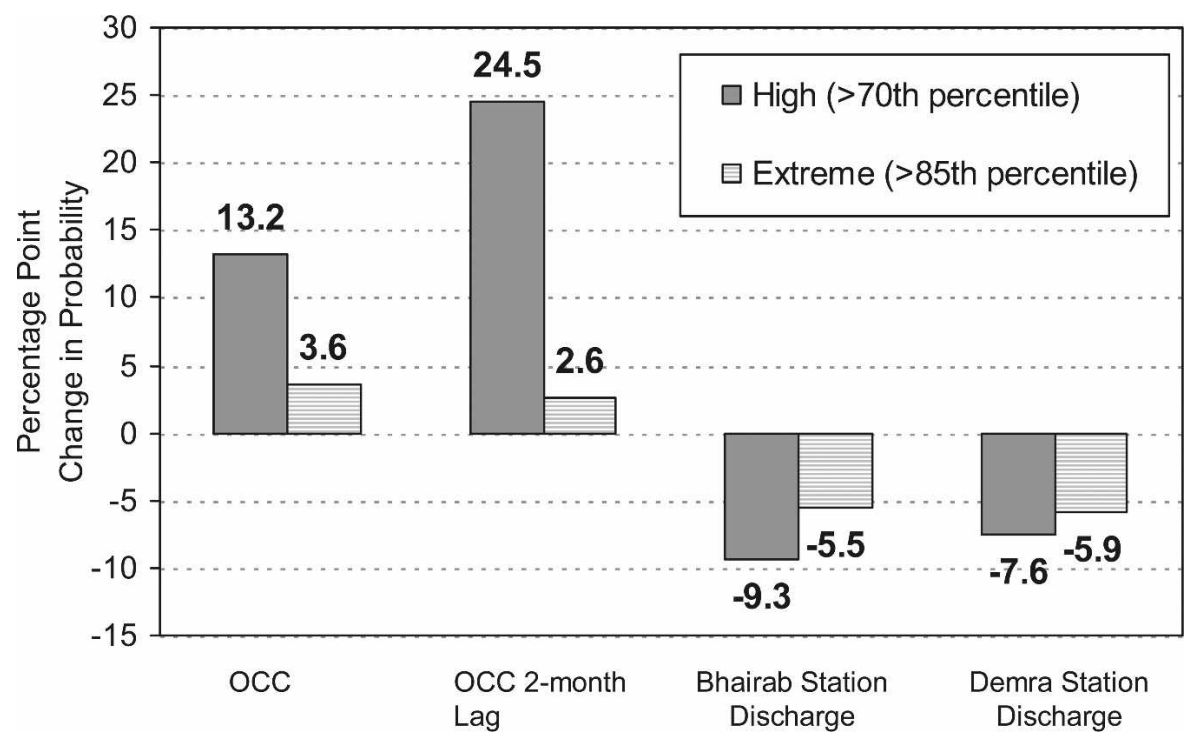

FIGURE 6. Effect of a standard deviation* increase in significant environmental factors on the probability of increasing cholera magnitude: Bangladesh.

* Standard Deviation Values: Ocean Chlorophyll Concentration $0.41 \mathrm{mg} / \mathrm{m}^{3}$; Bhairab Station Discharge $4870 \mathrm{~m}^{3} / \mathrm{s}$; Demra Station Discharge $360 \mathrm{~m}^{3} / \mathrm{s}$

also evident at a 2-month lag. These effects are stronger in the model of high cholera ( $>70$ th percentile) than in the model of extreme cholera ( $>85$ th percentile). Because lag effects might prove beneficial in the creation and implementation of an early warning system, this finding is particularly useful. Moreover, the effect of a change in 1 standard deviation of ocean chlorophyll concentration on the magnitude of the cholera outbreaks is 2-3 times greater than the effect of an increase in 1 standard deviation in river discharge, reaffirming the potential strength of this relationship. In contrast to the effects of chlorophyll, increases in river discharge are negatively associated with cholera. Although the effect size is smaller than that of ocean chlorophyll concentration, the impact of changes in river discharge remain almost constant in influencing a high or extreme monthly outbreak. These discharge stations are located upstream from the study site, and the relationship is consistent with what some have called a dilution effect. ${ }^{28}$ Unexpectedly, neither sea surface temperature nor sea surface height had a significant effect on the magnitude of cholera in Bangladesh. This finding differs from previous research that used a shorter time series on the impor-

TABLE 6

Relationship between cholera outbreaks and the environment in Hue, Vietnam

\begin{tabular}{lcrc}
\hline \multicolumn{1}{c}{ Variable } & $N$ & Bivariate & Multivariate \\
\hline River height 2-month lag & 228 & $-0.044^{* * *}(0.012)$ & \\
Sea surface temperature & 148 & $0.233^{* * *}(0.063)$ & $0.194 *(0.0934)$ \\
Sea surface height & 148 & $-0.029 *(0.012)$ & $-0.010(0.015)$ \\
Sea surface height & & & \\
$\quad$ 2-month lag & 228 & $-0.041^{* *}(0.014)$ & \\
Rainfall 2-month lag & 228 & $-0.004^{* * *}(0.001)$ & \\
Temperature & 100 & $0.183(0.044)$ & \\
Ocean chlorophyll & & & \\
$\quad$ concentration & 240 & $-1.18(1.16)$ & $13.94^{* * * \dagger}$ \\
Overall Wald $\chi^{2}$ & 148 & & \\
\hline
\end{tabular}

Results of Wald $\chi^{2}$ from probit model: $* P<0.05$, ${ }^{*} P<<0.01$, $* * * P<0.001$. Robust

standard errors in parentheses.
$\dagger$ Log-likelihood $=-30.19$. tance of these factors. Temperature and rainfall are also not associated with the magnitude of cholera in Bangladesh.

In Hue, unlike in Bangladesh, sea surface temperature has a highly significant effect on the probability of a cholera outbreak. It is the only environmental factor that is positively associated with an increased probability of cholera outbreaks in that study area. River height, sea surface height 2-month lag, and rainfall 2-month lag all have significant negative relationships with the probability of cholera outbreaks. The effect of an increase in sea surface temperature on the predicted probability of an outbreak is also revealing. An increase in $3.6^{\circ} \mathrm{C}$ raises the probability of an outbreak by $15 \%$, the strongest effect of any environmental factor. Also in contrast to Bangladesh, sea surface height is significantly and negatively related to cholera outbreaks. Interestingly, lag effects appear more significant in Hue than in Bangladesh; 2-month lag effects of river height, sea surface height, and rainfall all decrease the probability of cholera outbreaks by between $4 \%$ and $7 \%$. These factors may prove important for the development of a cholera prediction system for Hue and similar environments. Ocean chlorophyll concentration and ambient temperature have no significant relationship with the probability of cholera outbreaks in Hue.

Nha Trang shows significant variation in the effect of environmental factors on the probability of cholera outbreaks. Unlike Matlab or Hue, the effects of rain, river height, and river discharge appear to have a positive effect on cholera, increasing the likelihood of an outbreak. These factors also appear more important for Nha Trang. The effect of an increase in 1 standard deviation in each of these local environmental variables on the probability of cholera outbreaks is larger than the effect of similar increases in either Hue or Bangladesh. Increases in rain, Cai River height, and Cai River discharge impact the probability of cholera by approximately $10 \%$. Dinh River height has the most significant impact; an increase in 1 standard deviation $(39 \mathrm{~cm})$ increases the likelihood of an outbreak by more than $14 \%$; its 2 -month lag is 


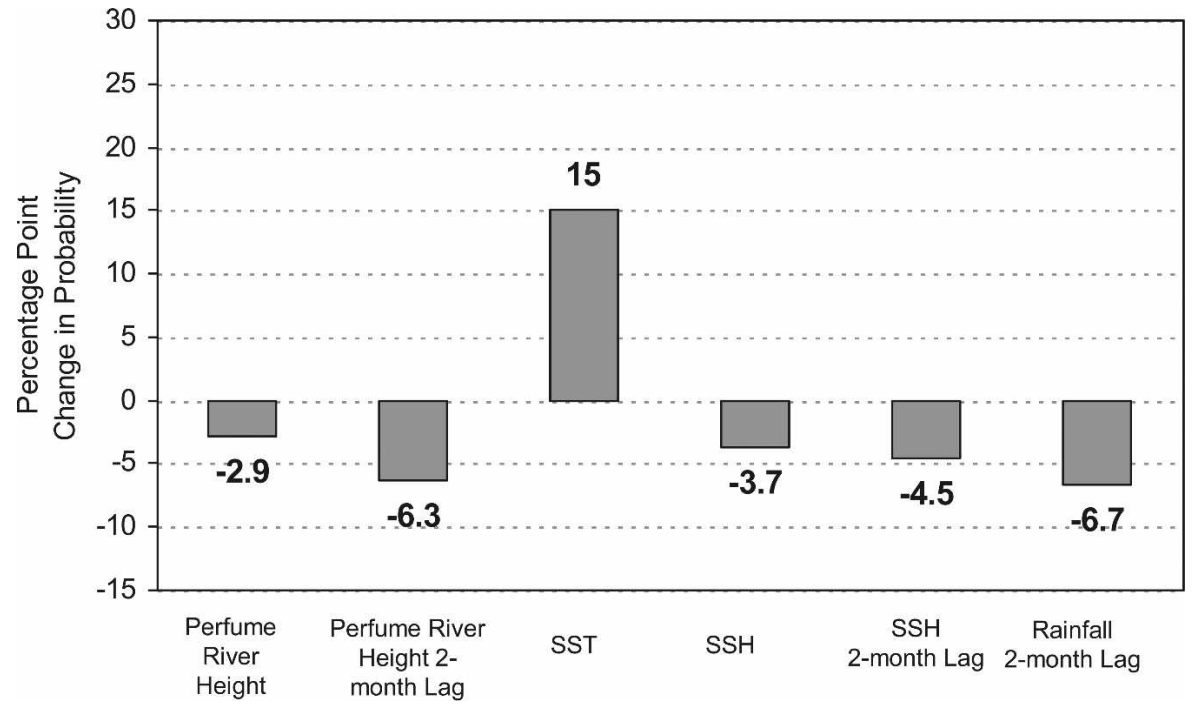

FIGURE 7. Effect of a standard deviation* increase in significant environmental factors on the probability of a cholera outbreak: Hue.

* Standard Deviation Values: Perfume River Height $31 \mathrm{~cm}$; Sea Surface Temperature 3.6 C; Sea Surface Height $13.8 \mathrm{~cm}$; Rainfall 2-month Lag $330.3 \mathrm{~cm}$.

almost as important, raising the probability by more than $10 \%$. These results and the strength of these effects are unexpected and suggest an inundation effect, perhaps related to Nha Trang's location on the coast. An inundation effect is when the aquatic environment is inundated with bacteria possibly caused by flooding. ${ }^{28}$ This is speculative because we do not have flooding data for Nha Trang. The divergence of Nha Trang results from those of the other research sites may show support for the strength of local-level factors in cholera outbreak. However, Nha Trang did not have many months of cholera compared with Hue or Matlab. Thus, environmental effects might not be detectible in areas with limited cholera.

There are several limitations to this study. The data set is relatively small because the satellite record is short; this limits the ability to achieve statistical significance. Because of these data-availability constraints, aggregation by month is necessary, potentially reducing variation in the data. However, despite the small sample size, the results of the initial analysis suggest that a larger sample would increase both the magnitude and significance of the results. With additional years of data, or the addition of weekly or daily satellite data, it is

TABLE 7

Relationship between cholera outbreaks and the environment in Nha Trang, Vietnam

\begin{tabular}{lcrl}
\hline \multicolumn{1}{c}{ Variable } & $N$ & \multicolumn{1}{c}{ Bivariate } & Multivariate \\
\hline Monthly rainfall & 131 & $0.002 *(0.001)$ & \\
& & & \\
Cai River height & 228 & $0.004 * *(0.002)$ & $0.0000186(0.002)$ \\
Dinh River height & 215 & $0.0123 * * *(0.003)$ & $0.0123 * * *(0.003)$ \\
Dinh River height & & & \\
$\quad$ 2-month lag & 215 & $0.008 * *(0.002)$ & \\
Dinh River discharge & 228 & $0.004 *(0.002)$ & \\
Sea surface temperature & 228 & $-0.007(0.032)$ & \\
Sea surface height & 148 & $-0.012(0.017)$ & \\
Temperature & 131 & $0.093(0.065)$ & \\
Overall Wald $\chi^{2}$ & 215 & & $20.45^{* * * \dagger}$ \\
\hline
\end{tabular}

Results of Wald $\chi^{2}$ from probit model; significance at $* P<0.05, * * P<0.01, * * * P<0.001$. Robust standard errors in parentheses.

$\dagger$ Log-likelihood $=-126.412$. expected that significant variables such as ocean chlorophyll, sea surface temperature, and river height could reveal stronger effects on cholera outbreaks and magnitude. These relationships may hold for similar tropical, coastal areas but may not be relevant for inland or non-endemic areas. Additionally, it is possible that these environmental factors have additional relationships, and the role of interaction and mediation are not explored in this analysis due to the limitations in data availability. Finally, the absence of cholera in Nha Trang since 1995 may suggest alternative explanations above and beyond environmental predictors (e.g., improved water quality, sanitation, and socioeconomic status of the population); these factors are not considered in this analysis.

\section{CONCLUSION}

This study shows that local-level environmental factors are important for predicting cholera outbreaks and magnitude. This finding is especially applicable in the endemic cholera area of Bangladesh where outbreaks are frequent and incidence is high. As our results suggest, in Bangladesh, the magnitude of the monthly cholera outbreaks is clearly related to the environment, and awareness of changes in factors such as ocean chlorophyll concentration and river discharge may lead to increased preparation for anomalous outbreak levels in the future. However, translation of this information into the development of a cholera early warning system poses complex challenges and may not be transferable to other endemic areas. In Vietnam, where cholera is sporadic and occurs with low incidence levels, it may be possible only to identify the necessary, but not sufficient, causes of outbreaks. In these types of situations, a cholera early warning system may not prove accurate or cost effective.

To further refine these models and encourage their utilization for early warning system development, future studies should examine possible interactive and mediating effects of environmental factors. The high correlations between environmental variables are suggestive of unexplored relation- 


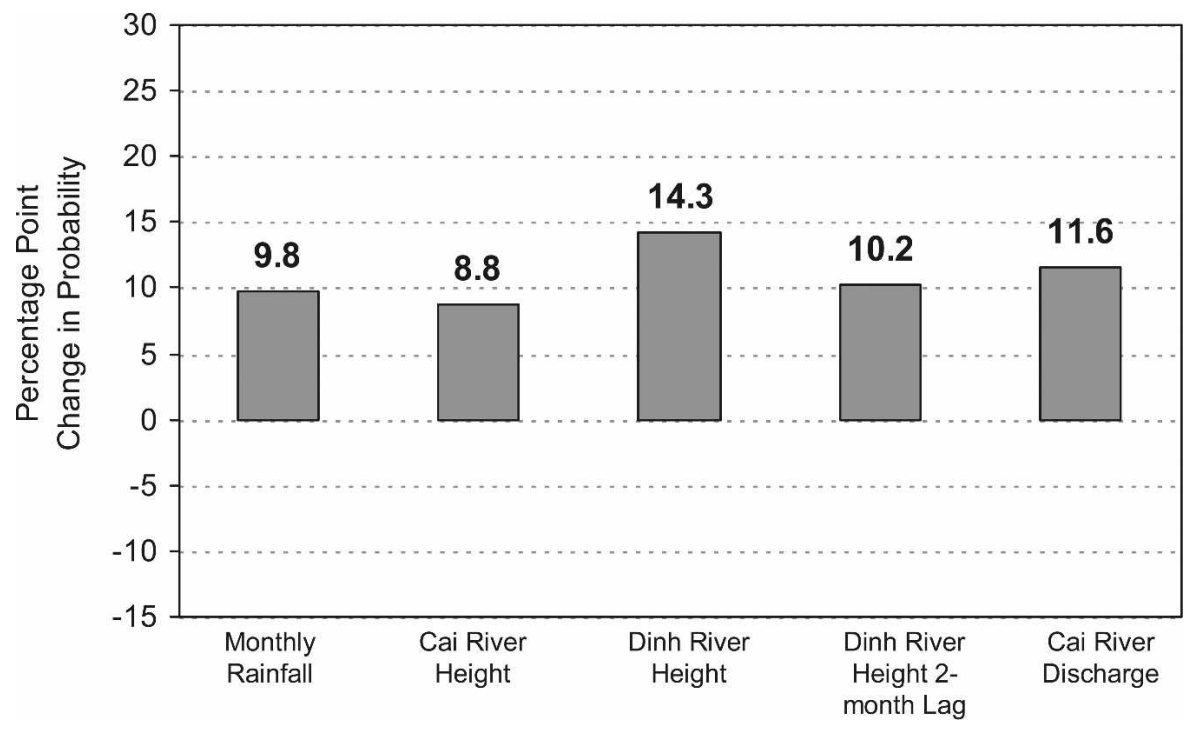

FIGURE 8. Effect of a standard deviation* increase in significant environmental factors on the probability of a cholera outbreak: Nha Trang. * Standard Deviation Values: Monthly Rainfall $121 \mathrm{~cm}$; Cai River Height $61 \mathrm{~cm}$; Dinh River Height $39 \mathrm{~cm}$; Cal River Discharge 85 cm.

ships. This will require a longer record of environmental data, a limiting factor in this study due to the limited history of satellite sensor information. Longer time series will also allow future studies to differentiate between the pre- and postmonsoon epidemics in endemic areas like Matlab to see if environmental drivers are the same during the different seasons. Investigation into within-site variation is also needed, and exploration of the differences in local- or neighborhoodlevel characteristics could prove informative and valuable. Inclusion of local-level population variables and utilization of multilevel models of neighborhood and climate effects would complement and enhance studies of these relationships. Overall, the results of this paper serve as a foundation for future studies of the local-level environmental and climactic influences on cholera. The possibility of a cholera early warning system exists because, in all study areas, there is a clear relationship with environmental parameters. However, the predictive model might be complex and might not work well in situations where cholera is relatively uncommon.

Received September 23, 2007. Accepted for publication January 16, 2008.

Acknowledgments: This work was supported by a grant from NOAA: Oceans and Human Health Program.

Authors' addresses: Caryl Feldacker, Mohammad Yunus, Peter Kim Streatfield, Vu DinhThiem, Do Gia Canh, and Mohammad Ali. Michael Emch, Department of Geography, 205 Saunders Hall, CB 3220, University of North Carolina-Chapel Hill, Chapel Hill, NC 27599, E-mail: emch@unc.edu and Carolina Population Center, University of North Carolina-Chapel Hill, North Carolina. Caryl Feldacker, Department of Health Behavior and Health Education, University of North Carolina-Chapel Hill, and Carolina Population Center, University of North Carolina at Chapel Hill, CB\# 8120, University Square, 123 West Franklin Street, Chapel Hill, NC 275162524, E-mail: caryl@unc.edu. Mohammed Yunis, ICDDR,B, Centre for Health and Population Research, Bangladesh, E-mail: myunus@icddrb.org. Peter Kim Streatfield, ICDDR,B, Centre for Health and Population Research, Bangladesh, E-mail: Streatfieldkims@icddrb.org. Vu Dinh Thiem and Do Gia Canh, National Institute of Hygiene and Epidemiology, Hanoi, Vietnam, E-mails: vudinthiem@hn.vnn.vn and Canh-uncddp2@hn.vnn.vn. Mohammad Ali, International Vaccine Institute, Seoul, Korea, E-mail: mali@ivi.int.
Reprint requests: Michael Emch, Department of Geography, 205 Saunders Hall, Campus Box 3220, University of North CarolinaChapel Hill, Chapel Hill, NC 27599, Telephone: +1 (919) 843-1010, Fax: +1 (919) 962-1537, E-mail: emch@unc.edu.

\section{REFERENCES}

1. Lobitz B, Beck L, Huq A, Wood B, Fuchs G, Faruque ASG, Colwell R, 2000. Climate and infectious disease: use of remote sensing for detection of Vibrio cholerae by indirect measurement. Proc Natl Acad Sci USA 97: 1438-1443.

2. WHO, 2004. Using climate to predict infectious disease outbreaks: a review. Communicable Diseases Surveillance and Response. Geneva: World Health Organization.

3. Emch M, Ali M, Park JK, Yunus M, Sack DA, Clemens JD, 2006. Relationship between neighbourhood-level killed oral cholera vaccine coverage and protective efficacy: evidence for herd immunity. Int J Epidemiol 35: 1044-1050.

4. Cavailler P, Lucas M, Perroud V, McChesney M, Ampuero S, Guerin PJ, Legros D, Nierle T, Mahoudeau C, Lab B, Kahozi P, Deen JL, von Seidlein L, Wang XY, Puri M, Ali M, Clemens JD, Songane F, Baptista A, Ismael F, Arreto AB, Chaignat $\mathrm{CL}, 2006$. Feasibility of a mass vaccination campaign using a two-dose oral cholera vaccine in an urban cholera-endemic setting in Mozambique. Vaccine 24: 4890-4895.

5. Emch M, Ali M, 2001. Spatial and temporal patterns of diarrheal disease in Matlab, Bangladesh. Environ Plan A 33: 339-350.

6. Islam MS, Drasar BS, Sack RB, 1993. The aquatic environment as a reservoir of Vibrio cholerae: a review. J Diarrhoeal Dis Res 11: 197-206.

7. Longini IM Jr, Yunus M, Zaman K, Siddique AK, Sack RB, Nizam A, 2002. Epidemic and endemic cholera trends over a 33-year period in Bangladesh. J Infect Dis 186: 246-251.

8. Merson MH, Black RE, Khan MU, Huq I, 1980. Enterotoxigenic Escherichia coli diarrhea: acquired immunity and transmission in an endemic area. Cholera and Related Diarrheas: Molecular Basis of a Global Health Problem. 43rd Nobel Symposium. Basel, Switzerland: S. Karger, 34-45.

9. Colwell RR, Huq A, 1994. Environmental reservoir of Vibrio cholerae-the causative agent of cholera. Ann NY Acad Sci 740: $44-54$

10. Islam MS, Drasar BS, Bradley DJ, 1989. Attachment of toxigenic Vibrio cholerae O1 to various freshwater plants and survival with a filamentous green alga, Rhizoclonium fontanum. J Trop Med Hyg 92: 396-401.

11. Islam MS, Drasar BS, Bradley DJ, 1990. Survival of toxigenic Vibrio cholerae $\mathrm{O} 1$ with a common duckweed, Lemna minor, 
in artificial aquatic ecosystems. Trans $R$ Soc Trop Med Hyg 84: 422-424.

12. Khan MU, 1981. Role of water supply and sanitation in the incidence of cholera in refugee camps. Scientific Report 45. Dhaka, Bangladesh: International Centre for Diarrhoeal Disease Research.

13. Islam MS, Drasar BS, Sack RB, 1994. Probable Role of bluegreen-algae in maintaining endemicity and seasonality of cholera in Bangladesh—a hypothesis. J Diarrhoeal Dis Res 12: 245256.

14. Koelle K, Pascual M, 2004. Disentangling extrinsic from intrinsic factors in disease dynamics: a nonlinear time series approach with an application to cholera. Am Nat 163: 901-913.

15. Islam MS, Hasan MK, Miah MA, Qadri F, Yunus M, Sack RB, Albert MJ, 1993. Isolation of Vibrio cholerae O139 Bengal from water in Bangladesh. Lancet 342: 430.

16. Nalin DR, Daya V, Reid A, Levine MM, Cisneros L, 1979. Adsorption and growth of Vibrio cholerae on chitin. Infect Immun 25: $768-770$.

17. Nalin DR, 1976. Cholera, copepods, and chitinase. Lancet 2: 958.

18. Huq A, Colwell RR, 1996. Vibrios in the marine and estuarine environment: tracking Vibrio cholerae. Ecosyst Health 2: 198214.

19. Kiorboe T, Nielsen TG, 1994. Regulation of zooplankton biomass and production in a temperate, coastal ecosystem. 1. Copepods. Limnol Oceanogr 39: 493-507.

20. Faruque SM, Naser IB, Islam MJ, Faruque ASG, Ghosh AN, Nair GB, Sack DA, Mekalanos JJ, 2005. Seasonal epidemics of cholera inversely correlate with the prevalence of environmental cholera phages. Proc Natl Acad Sci USA 102: 1702-1707.
21. Chakraborty S, Mukhopadhyay AK, Bhadra RK, Ghosh AN, Mitra R, Shimada T, Yamasaki S, Faruque SM, Takeda Y, Colwell RR, Nair GB, 2000. Virulence genes in environmental strains of Vibrio cholerae. Appl Environ Microbiol 66: 40224028.

22. Huq A, Xu B, Chowdhury MAR, Islam MS, Montilla R, Colwell RR, 1996. A simple filtration method to remove planktonassociated Vibrio cholerae in raw water supplies in developing countries. Appl Environ Microbiol 62: 2508-2512.

23. Islam MS, Talukder KA, Khan NH, Mahmud ZH, Rahman MZ, Nair GB, Siddique AK, Yunus M, Sack DA, Sack RB, Huq A, Colwell RR, 2004. Variation of toxigenic Vibrio cholerae O1 in the aquatic environment of Bangladesh and its correlation with the clinical strains. Microbiol Immunol 48: 773-777.

24. Miller CJ, Drasar BS, Feachem RG, 1982. Cholera and estuarine salinity in Calcutta and London. Lancet 1: 1216-1218.

25. Faruque SM, Albert MJ, Mekalanos JJ, 1998. Epidemiology, genetics, and ecology of toxigenic Vibrio cholerae. Microbiol Mol Biol Rev 62: 1301-1314.

26. Lipp EK, Huq A, Colwell RR, 2002. Effects of global climate on infectious disease: the cholera model. Clin Microbiol Rev 15: 757.

27. Miller CJ, Drasar BS, Feachem RG, 1984. Response of toxigenic Vibrio cholerae $\mathrm{O} 1$ to physico-chemical stresses in aquatic environments. J Hyg (Lond) 93: 475-495.

28. Ruiz-Moreno D, Pascual M, Bouma M, Dobson A, Cash B, 2007. Cholera seasonality in Madras (1901-1940): dual role for rainfall in endemic and epidemic regions. EcoHealth 4: 52-62.

29. Ai CR, Norton EC, 2003. Interaction terms in logit and probit models. Econ Lett 80: 123-129. 